\title{
An experimental investigation on the effect of ferrofluids on the efficiency of novel parabolic trough solar collector under laminar flow conditions
}

\author{
Mustafa Alsaady ${ }^{1,2}$, Rong $\mathrm{Fu}^{1}$, Zeyu Liu ${ }^{1}$, Yuying Yan $^{1 *}$, Shenyi $\mathrm{Wu}^{1}$, Rabah Boukhanouf ${ }^{1}$ \\ ${ }^{1}$ Fluids \& Thermal Engineering Research group, Faculty of Engineering, University of Nottingham, UK \\ ${ }^{2}$ Chemical Engineering Department, Faculty of Engineering, University of Jeddah, Saudi Arabia \\ *corresponding yuying.yan@nottingham.ac.uk, ezxma5@exmail.nottingham.ac.uk
}

\begin{abstract}
:
The paper is related to the use of magnetic nanofluids (ferrofluids) in a direct absorption solar parabolic trough collectors enhances thermal efficiency compared to conventional solar collectors. By applying the right magnetic intensity and magnetic field direction, the thermal conductivity of the fluid increased higher than typical nanofluids. Moreover, the ferrofluids exhibit excellent optical properties. The external magnetic source is installed to alter the thermos-physical properties of the fluid, and the absorber tube does not have selective surface allowing ferrofluids to absorb the incoming solar irradiance directly. In this paper, an experimental investigation of the performance of direct absorption solar collector using ferrofluids as an absorber. Various nanoparticle concentrations $0 \%$ to $1 \mathrm{vol} \%$ at the operational temperatures between $19^{\circ} \mathrm{C}$ and $40^{\circ} \mathrm{C}$ were used in the current study. The results show that using ferrofluids as a heat transfer fluid increases the efficiency of solar collectors. In the presence of the external magnetic field, the solar collector efficiency increases to the maximum, $25 \%$ higher than the conventional parabolic trough. At higher temperatures, the ferrofluids show much better efficiency than conventional heat transfer fluid. The study indicated that nanofluids, even of low-content, have good absorption of solar radiation, and can improve the outlet temperatures and system efficiencies.
\end{abstract}

Keywords: solar energy, parabolic trough, ferrofluids 


\section{Introduction}

The demand for modern energy services is increasing rapidly. Solar energy has the potential to meet a significant portion of the world's energy demand. Solar energy is one of the cleanest renewable forms with little or no impact on the environment. Concentrated Solar Power (CSP) is one of the methods to harvest sun's energy. CSP systems have the advantage of easier energy storage compared to photovoltaic (PV) systems. Several CSP technologies have been studied and evolved, and others have been successfully used commercially. CSP technologies include the parabolic trough systems, parabolic dish systems, solar tower systems and linear Fresnel systems [1].

The most commercially and technically developed CSP technology is the parabolic trough technology. Parabolic trough is not only effective in power generation but also useful for industrial process heat application. The temperature ranges for industrial process heat applications are between $70^{\circ} \mathrm{C}$ and $250^{\circ} \mathrm{C}[2,3]$. A comprehensive review about Parabolic trough collector was published recently [4]. The successful operation of the first solar electricity generation system (SEGS) in California's Mojave Desert was the reason for the technical and commercial success of parabolic trough systems. However, the cost of energy generated by CSP systems is higher than conventional energy sources. Several research and development initiatives have the goal to reduce the cost of energy from these systems by roughly $75 \%$ to become competitive with conventional energy in the future $[5,6]$. Many researchers work on improving the performance of CSP systems and make them cost competitive.

One of the methods to reduce cost is increasing the heat transfer performance of parabolic trough systems. Increasing the heat transfer performance will decrease the absorber surface temperature and subsequently reduce the receiver thermal loss particularly at the high operation temperatures $[7,8]$. This could be achieved by enhancing the convective heat transfer in the absorber tube. 
Researchers have tried modifying the surface and the design of the absorber tube to enhance the convective heat transfer [9-13]. Others have used a different kind of heat transfer fluids such as molten salt or nanofluids to improve the performance of heat transfer [14].

In recent years, many researchers have investigated the effects of nanofluids on the enhancement of heat transfer in thermal engineering devices, both theoretically and experimentally. Nanofluids are a mixture of Nano-sized particles $(1-100 \mathrm{~nm})$ in a conventional heat transfer mediums. Heat transfer can be enhanced by increasing the thermal properties of heat transfer fluid (nanofluids). Nanofluids illustrating excellent thermo-physical properties are appropriate to enhance the efficiency of any thermal management systems by selecting base fluids with suitable nanoparticle materials, dispersion agents, nanoparticle sizes, and particle volume fraction $[15,16]$.

Harvesting the solar energy using nanofluids has been the focus of few researchers. An overall review of the performance of solar collector using nanofluids was presented [17]. There are two methods to harvest the solar energy when nanofluids are used, which are direct absorber collectors and non-direct absorber collectors. Non-direct absorber collectors are the conventional solar collector with an absorber that has a selective surface to absorb the solar radiation. Direct solar collectors use a transparent receiver to allow nanofluids to absorb the solar radiation. Nanofluids show very good optical properties to absorb the solar radiation. In a fluid depth of $10 \mathrm{~mm}, 90 \%$ of the solar radiation was absorbed by nanofluids with $0.1 \%$ volume fraction [18].

A nanofluids-based concentrating solar system with direct absorber was numerically compared with a conventional one [19]. The results show that the use of nanofluids in the receiver can improve the efficiency by $10 \%$. They also concluded that for 10-100 MWe power plants, using graphite/therminol VP-1 nanofluids with volume fractions approximately to $0.001 \%$ or less could be beneficial. A numerical study using FLUENT was developed to investigate the heat transfer 
performance of $\mathrm{A} 12 \mathrm{O} 3 /$ synthetic oil nanofluids in a trough collector tube with a non-uniform heat flux. Various nanoparticle concentrations and operation temperature were used in the study [20]. Three-dimensional Navier-Stokes mass, momentum, and energy equations were solved. The study used an LS-2 parabolic trough collector module, tested in the AZTRAK rotating test platform at SNL by Dudley et al. The heat transfer coefficient is increased as the concentration of the nanoparticles in the base fluid is increased. The heat transfer coefficient decreases with increasing operation temperature. Recently, a thermodynamic analysis using the entropy generation minimization method for a parabolic trough receiver tube was carried on. A synthetic oil-Al2O3 nanofluid was used as heat transfer medium. The results show an improvement in thermal efficiency up to $7.6 \%$. A maximum Reynolds number was obtained for which the entropy generation in the absorber is at a minimum [21].

A unique type of nanofluids is ferrofluids. Ferrofluids content ferromagnetic nanoparticles that exhibit higher thermos-physical properties compared to the conventional nanofluids. By applying the right magnetic intensity and magnetic field direction, the thermal conductivity of the fluid enhanced more than typical nanofluids [22]. The thermal conductivity enhanced by $300 \%$ when ferrofluids with $6 \%$ volume fraction were exposed to external magnetic field [23]. The aim of this work is to modify parabolic trough collector to increase the heat transfer performance by using ferrofluids. In particular, a modified parabolic trough collector using water $\mathrm{Fe} 3 \mathrm{O} 4$ nanofluids was built, and its efficiency was measured under the different working condition, according to BS EN ISO 9806:2013. The comparison between the heat transfer fluids has been performed in controlled and standard conditions, reducing the possibility of error.

\section{Ferrofluids preparation}


The magnetite nanoparticles $\mathrm{Fe}_{3} \mathrm{O}_{4}$ were prepared using co-precipitation methods. The average diameter of nanoparticles was $10 \mathrm{~nm}$. The surface of the nanoparticle was coated by Sodium dodecyl SDS, and suspended in water. SDS increase the stability of the suspension and avoid sedimentation of particles. Using a static position method, the stability of ferrofluids was investigated. The ferrofluids were left standing in a container for four months. The distance or color difference in sedimentation within ferrofluids was observed by naked eye. The change of concentration is barely noticed. SDS produced a lot of bubbles when used in the solar collector. Therefore, a defoamer (DF, Antifoam B Silicone Emulsion) was added to suppress the bubble formation. Rh DF concentration was $15 \%$ of the weight of the added SDS. The test of ferrofluids with and without deformer is presented.

\section{Experimental Setup}

The parabolic trough collector (PTC) used in the experiment consisted of a sheet of the reflective mirror with a parabolic shape, absorber tube, and electromagnets as shown in Fig.1. The reflective mirror was $1 \mathrm{~mm}$ thick high impact polystyrene sheet with white painting on the back. The reflectivity of the mirror is not considered in this study. At the focal line of the concentrator, an absorber tube was placed. The absorber used was a borosilicate glass tube to allow ferrofluids to absorb the solar radiation. No envelope was utilized in this experiment. Three electromagnets are placed in the entrance, middle, and the outlet of the absorber. The electromagnet is air core solenoid with an inner diameter close to the outer diameter of the absorber tube, allowing the absorber tube to enter into the electromagnet. The electromagnet generates a uniform magnetic field when a current is passing through the coils. Adjustable DC power supply is used to control the current applied to the electromagnet with maximum current of 5A. A solar light simulator of high flux irradiation was developed. Some experimental tests were carried out for various distances 
of the light surface from the simulator surface to investigate the unevenness of variations in light distribution. A pyranometer was used to study the solar radiation. The maximum unevenness error percentage was about $12.3 \%$, which is in a good agreement within the permissible limits of $15 \%$ provided by British standards for testing a solar simulator. The solar simulator turned on and kept for 30 minutes before taking any readings.

An experimental setup was developed based on BS EN ISO 9806:2013 to study the performance of the proposed ferrofluids parabolic trough. Fig.2 shows the schematic of the experimental setup. The experimental set up consisted of the water tank, pipeline system, water pump, parabolic trough, heat exchanger, chiller, chiller pump, and measurement system. A solenoid valve was used to adjust the flow of ferrofluids. Flow rate is measured by an ultrasonic flow meter, FLOWNETIX 100. The temperatures in the inlet, outlet and atmosphere were measured by non-magnetic type $\mathrm{T}$ thermocouples. The pressure was measured by a pressure transducer, PTX 14 DRUCK. The chiller used was water chiller, Hailea $\mathrm{HC}$ series chiller.

A steady -state method was used to calculate the parabolic trough efficiency, according to BS EN ISO 9806:2013 standard. The test condition is shown in Table 1.

The usable heat extracted by the parabolic trough, $\dot{Q}_{U}$, is calculated by Eq. (1)

$\dot{Q}_{U}=\dot{m}_{f} C_{p, f}\left(T_{\text {out }}-T_{\text {in }}\right)$

Where $\dot{m}_{f}$ is the mass flow of ferrofluids $C_{p, f}$ is the specific heat capacity of ferrofluids which is calculated by Eq. 2

$$
\mathrm{C}_{\mathrm{p}, \mathrm{f}}=(1-\varphi) C_{p, w}+\varphi C_{p, n p}
$$

Where $C_{p, w}$ and $C_{p, n p}$ are specific heat capacity of water and nanoparticles, respectively. The heat capacity is effected by the temperature. Therefore, the heat capacity calculated at the mean temperature $T_{m}$ which calculated by Eq.3 
$T_{m}=\frac{T_{\text {in }}+T_{\text {out }}}{2}$

The thermal efficiency can be calculated by Eq. 4

$\eta=\frac{\dot{Q}_{U}}{I_{D} A_{C}}$

Where $\eta$ is the efficiency of the parabolic trough, $I_{D}$ is the direct solar radiation and $A_{C}$ is the area of the collector.

The solar radiation uncertainty is less than $2 \%$. The uncertainty of mass flow is less than $1 \%$. Uncertainties for inlet and outlet temperatures were less than $0.1{ }^{\circ} \mathrm{C}$. Complex uncertainty was calculated by Eq. 5 and was between $1 \%$ and $5.2 \%$

$U_{\eta}=\sqrt{\left(\frac{\partial \eta}{\partial \dot{m}_{f}} U_{\dot{m}}\right)^{2}+\left(\frac{\partial \eta}{\partial I_{D}} U_{I_{D}}\right)^{2}+\left(\frac{\partial \eta}{\partial T_{\text {out }}} U_{T_{\text {out }}}\right)^{2}+\left(\frac{\partial \eta}{\partial T_{\text {in }}} U_{T_{\text {in }}}\right)^{2}}$

Table 1 Parameters of the parabolic trough and test condition

\begin{tabular}{lc}
\hline \multicolumn{1}{c}{ Parameters } & Values \\
\hline Length of the receiver & $500 \mathrm{~mm}$ \\
Width of the aperture & $250 \mathrm{~mm}$ \\
outer Diameter of the absorber & $15 \mathrm{~mm}$ \\
Solar irradiance & $1000 \mathrm{~W} / \mathrm{m}^{2}$ \\
Mass flow & $0.02 \mathrm{~kg} / \mathrm{s}$ \\
Magnetic field intensity & $3.146 .28,10.47 \mathrm{mT}$
\end{tabular}

\section{Result and discussion}

The efficiency of the parabolic trough was investigated with distilled water- $\mathrm{Fe}_{3} \mathrm{O}_{4}$ ferrofluid at a concentration of $0 \%$ and $0.05 \mathrm{Vol} \%$, and a magnetic field intensity of 0 and $10.5 \mathrm{mT}$. The magnetic field intensity was similar to a study on the thermal conductivity of the ferrofluids [24].The mass flow rate was close to those used in previous studies on solar collector using nanofluids [25,26]. Thermal efficiency analysis of parabolic trough, with water and ferrofluids, was carried out by increasing the difference between the mean temperature $T_{m}$ and the temperature of the atmosphere. 
The test started by turning on the sun simulator, the ferrofluids pump, and the chiller pump. the sun simulator needs 30 minutes to reach the maximum intensity and remain constant. The chiller was used to assure a constant inlet temperature in the time of measurements. Then the chiller was adjusted to increase the inlet temperature. Fig. 3 shows the efficiency of parabolic trough for both water and $\mathrm{Fe}_{3} \mathrm{O}_{4}$-water ferrofluids $0.05 \%$ with no magnetic field applied under laminar flow condition. by using the water, the highest efficiency value $10 \%$ was obtained. At a $\mathrm{Tm} 0.1{ }^{\circ} \mathrm{C}$ $\mathrm{m} 2 / \mathrm{W}$ The lowest efficiency value has been obtained, $0 \%$. in this case inlet temperature, ambient temperatures were $30.04^{\circ} \mathrm{C}$ and $20.23^{\circ} \mathrm{C}$ respectively.

By using ferrofluids, $0.05 \%$ as heat transfer fluid with no external magnetic field applied the highest efficiency of $16 \%$ was obtained. The lowest efficiency value has been obtained, $6 \%$. in this case inlet temperature, ambient temperatures were $30.04^{\circ} \mathrm{C}$ and $20.23^{\circ} \mathrm{C}$ respectively. When the difference between the mean temperature and the ambient temperature increase to $6{ }^{\circ} \mathrm{C}_{,} \mathrm{Fe}_{3} \mathrm{O}_{4}$ water ferrofluids $0.05 \%$ shows much higher enchantment compared to water, around $16 \%$ higher. Fig4 shows the result of $\mathrm{Fe}_{3} \mathrm{O}_{4}$-water ferrofluids $0.05 \%$ with applied magnetic field. The efficiency increases with increasing the magnetic field intensity when the orientation of the magnetic field is parallel to the direction of the flow. The maximum efficiencies of $30 \%, 35 \%$, and $040 \%$ for $3.14 \mathrm{mT}, 6.28 \mathrm{mT}$, and $10.47 \mathrm{mT}$ respectively. Water was also used with external magnetic field. There is no effect of magnetic field on the measurements.

Nanoparticles enhance the thermophysical properties of the fluid which allow the heat to transfer faster from the absorber surface to the fluid. Many mechanisms are put forward to account the enhancement in the thermo-physical properties of ferrofluids, which are ballistic phonon transport, Brownian motion induced micro-convection and the aggregation of nanoparticles. Systematic studies reveal that the conduction path through agglomerates is one of the most significant factors 
responsible for the dramatic enchantment [24,27]. The magnetic field induced the chain-like structure f nanoparticles of magnetite in magnetic nanofluids which allow heat to transfer faster through the fluid. When the magnetic field was increased the chain length increase, creating more bridge of thermal energy conduction along the magnetic field direction. Moreover, ferrofluids show enhancement in optical properties (absorption and scattering) compared to base fluids. The enhancement is a function of nanoparticles size, concentration and the optical path length $[18,28]$. For all these reasons thermal efficiency of solar collector increases by using ferrofluids. Increasing the magnetic field further will not affect the thermal efficiency because the particles reached to a saturation magnetization.

\section{Conclusion}

An innovative direct absorption parabolic trough collector, uses ferrofluids as heat transfer fluid and absorber, was built. An experimental comparison of thermal efficiency between two heat transfer fluids $\mathrm{Fe}_{3} \mathrm{O}_{4}$-water ferrofluids with $0.05 \%$ and distilled water, working in the same parabolic trough, has been performed. This parabolic trough benefits from the magnetic and optical property of ferrofluids which enhance the thermal efficiency of the collector. The results show that using ferrofluids as a heat transfer fluid increases the efficiency of solar collectors. The thermal efficiency rose $16 \%$ maximum when ferrofluids were used without external magnetic field compared to base fluid. In the presence of the external magnetic field, the solar collector efficiency increases to the maximum, $40 \%$ higher than the conventional parabolic trough. At higher temperatures, the ferrofluids show much better efficiency than conventional heat transfer fluid. The ferrofluids show better heat transfer coefficient and decrease the surface temperature of the absorber. The modification of the new parabolic trough consists of adding an electromagnetics to the absorber tube because the external magnetic field would enhance the thermo-physical 
properties of the ferrofluids. Efficiency was calculated at various reduced temperature difference.

Ferrofluids are more efficient at high operation temperatures.

\section{Reference}

[1] Kalogirou, S. A. Solar energy engineering: processes and systems. (Academic Press, 2013).

[2] Silva, R., Berenguel, M., Pérez, M. \& Fernández-Garcia, A. Thermo-economic design optimization of parabolic trough solar plants for industrial process heat applications with memetic algorithms. Applied Energy 113, 603-614 (2014).

[3] Coccia, G., Di Nicola, G. \& Sotte, M. Design, manufacture, and test of a prototype for a parabolic trough collector for industrial process heat. Renewable Energy 74, 727-736 (2015).

[4] Jebasingh, V. \& Herbert, G. J. A review of solar parabolic trough collector. Renewable and Sustainable Energy Reviews 54, 1085-1091 (2016).

[5] U S Department of Energy [accessed 01.12.13] (http://www1.eere.energy.gov/solar/sunshot/csp baseload skyfuel.html).

[6] Price, H. et al. Advances in parabolic trough solar power technology. Journal of solar energy engineering 124, 109-125 (2002).

[7] Dudley, V., Kolb, G., Sloan, M. \& Kearney, D. SEGS LS2 solar collector-Test results. Report of Sandia National Laboratories, Report No. SANDIA94-1884 (1994).

[8] Padilla, R. V., Demirkaya, G., Goswami, D. Y., Stefanakos, E. \& Rahman, M. M. Heat transfer analysis of parabolic trough solar receiver. Applied Energy 88, 5097-5110, doi:10.1016/j.apenergy.2011.07.012 (2011).

[9] Kumar, K. R. \& Reddy, K. Thermal analysis of solar parabolic trough with porous disc receiver. Applied Energy 86, 1804-1812 (2009).

[10] Muñoz, J. \& Abánades, A. Analysis of internal helically finned tubes for parabolic trough design by CFD tools. Applied energy 88, 4139-4149 (2011).

[11] Cheng, Z., He, Y. \& Cui, F. Numerical study of heat transfer enhancement by unilateral longitudinal vortex generators inside parabolic trough solar receivers. International journal of heat and mass transfer 55, 5631-5641 (2012).

[12] Fuqiang, W., Qingzhi, L., Huaizhi, H. \& Jianyu, T. Parabolic trough receiver with corrugated tube for improving heat transfer and thermal deformation characteristics. Applied Energy 164, 411424 (2016).

[13] Zou, B., Dong, J., Yao, Y. \& Jiang, Y. An experimental investigation on a small-sized parabolic trough solar collector for water heating in cold areas. Applied Energy 163, 396-407 (2016).

[14] Wu, Y.-T., Liu, S.-W., Xiong, Y.-X., Ma, C.-F. \& Ding, Y.-L. Experimental study on the heat transfer characteristics of a low melting point salt in a parabolic trough solar collector system. Applied Thermal Engineering 89, 748-754 (2015).

[15] Lomascolo, M., Colangelo, G., Milanese, M. \& de Risi, A. Review of heat transfer in nanofluids: conductive, convective and radiative experimental results. Renewable and Sustainable Energy Reviews 43, 1182-1198 (2015).

[16] Hussien, A. A., Abdullah, M. Z. \& Moh'd A, A.-N. Single-phase heat transfer enhancement in micro/minichannels using nanofluids: Theory and applications. Applied Energy 164, 733-755 (2016).

[17] Javadi, F. S., Saidur, R. \& Kamalisarvestani, M. Investigating performance improvement of solar collectors by using nanofluids. Renewable and Sustainable Energy Reviews 28, 232-245 (2013). 
[18] Zhang, L. et al. Radiative properties of ionic liquid-based nanofluids for medium-to-hightemperature direct absorption solar collectors. Solar Energy Materials and Solar Cells 130, 521528 (2014).

[19] Taylor, R. A. et al. Applicability of nanofluids in high flux solar collectors. Journal of Renewable and Sustainable Energy 3, 023104 (2011).

[20] Sokhansefat, T., Kasaeian, A. B. \& Kowsary, F. Heat transfer enhancement in parabolic trough collector tube using Al2O3/synthetic oil nanofluid. Renewable and Sustainable Energy Reviews 33, 636-644 (2014).

[21] Mwesigye, A., Huan, Z. \& Meyer, J. P. Thermodynamic optimisation of the performance of a parabolic trough receiver using synthetic oil-Al 203 nanofluid. Applied Energy 156, 398-412 (2015).

[22] Alsaady, M., Fu, R., Li, B., Boukhanouf, R. \& Yan, Y. Thermo-physical properties and thermomagnetic convection of ferrofluid. Applied Thermal Engineering (2014).

[23] Philip, J., Shima, P. D. \& Raj, B. Enhancement of thermal conductivity in magnetite based nanofluid due to chainlike structures. Applied Physics Letters 91, 203108, doi:10.1063/1.2812699 (2007).

[24] Nkurikiyimfura, I., Wang, Y. \& Pan, Z. Effect of chain-like magnetite nanoparticle aggregates on thermal conductivity of magnetic nanofluid in magnetic field. Experimental Thermal and Fluid Science 44, 607-612, doi:10.1016/j.expthermflusci.2012.08.024 (2013).

[25] Colangelo, G., Favale, E., de Risi, A. \& Laforgia, D. A new solution for reduced sedimentation flat panel solar thermal collector using nanofluids. Applied Energy 111, 80-93 (2013).

[26] Colangelo, G. et al. Experimental test of an innovative high concentration nanofluid solar collector. Applied Energy 154, 874-881 (2015).

[27] Philip, J., Shima, P. D. \& Raj, B. Evidence for enhanced thermal conduction through percolating structures in nanofluids. Nanotechnology 19, 305706 (2008).

[28] Hordy, N., Rabilloud, D., Meunier, J.-L. \& Coulombe, S. High temperature and long-term stability of carbon nanotube nanofluids for direct absorption solar thermal collectors. Solar Energy 105, 82-90 (2014). 


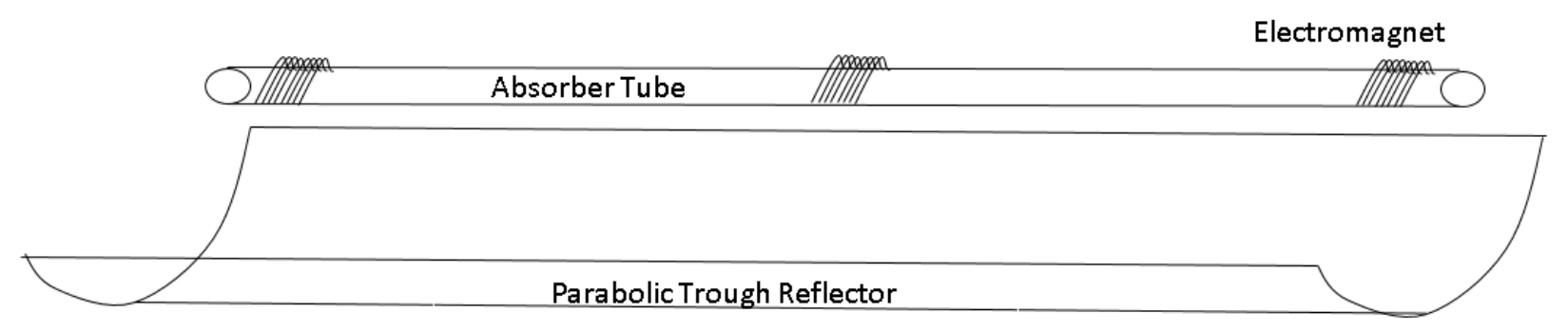

Figure 1 Schematic of proposed parabolic trough Collector 

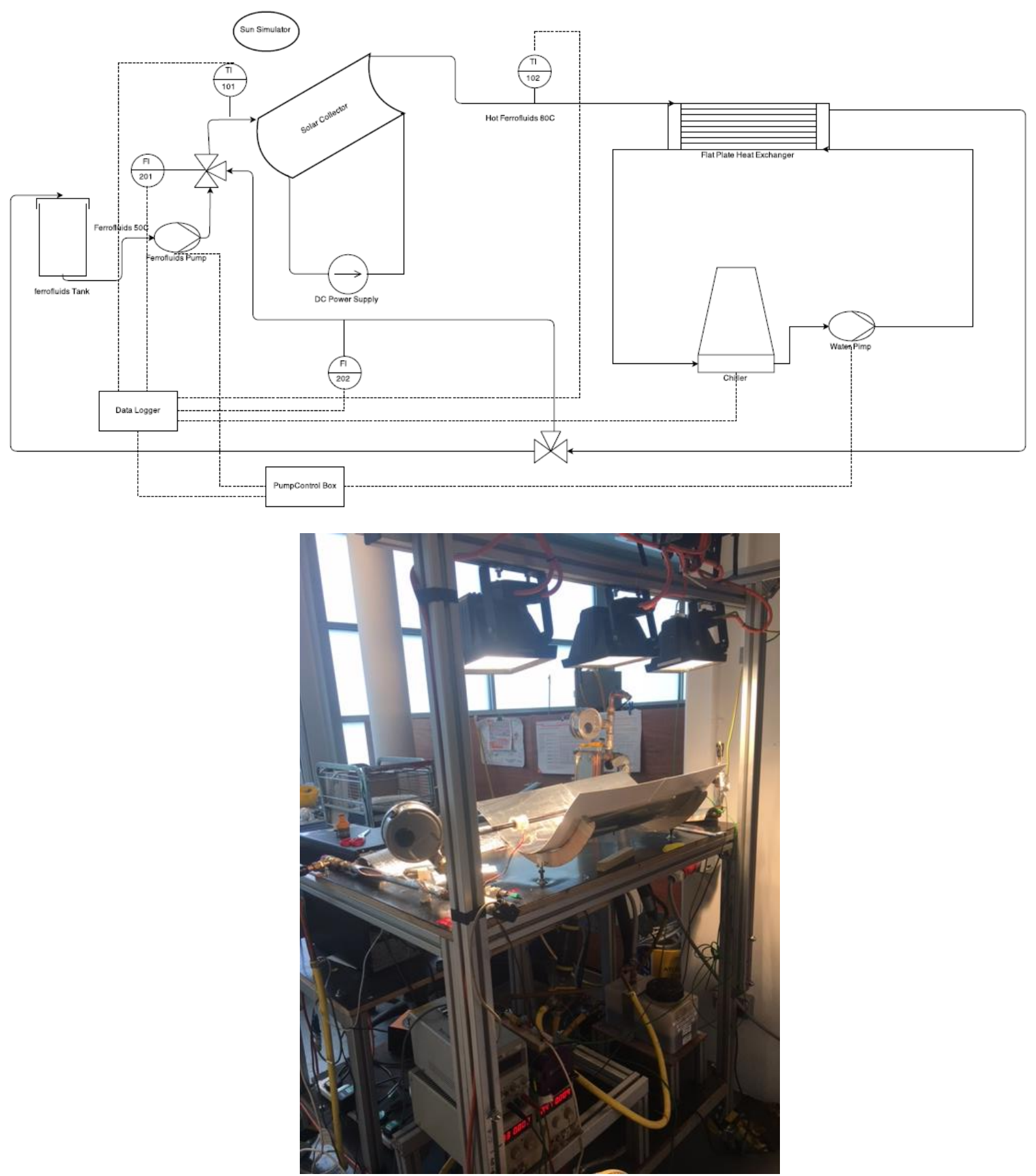

Figure 2 Schematic and photograph of the experimental setup 


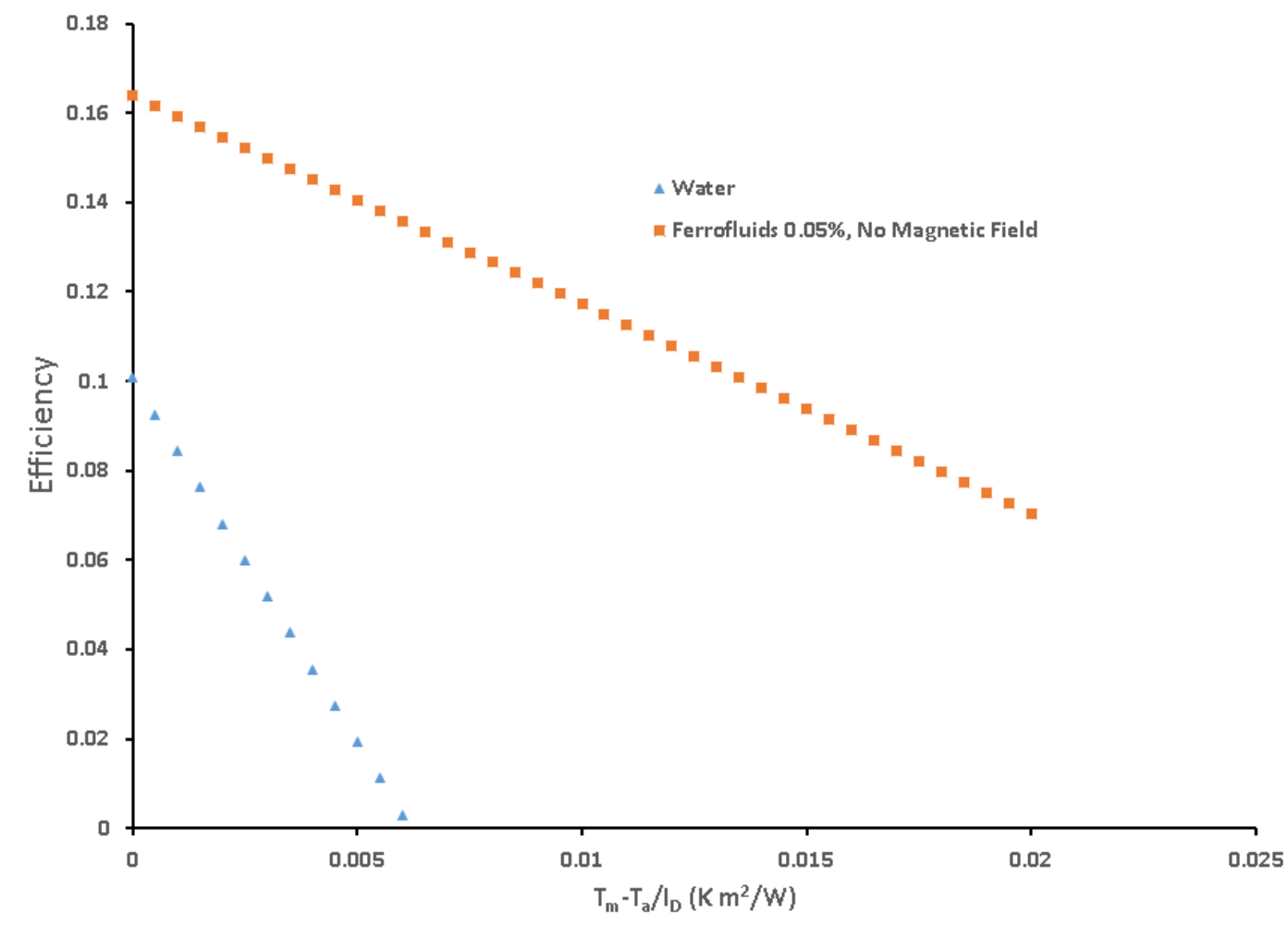

Figure 3: Thermal Efficiency of the parabolic trough with Water and Ferrofluids without Applied external magnetic field in the laminar region. 


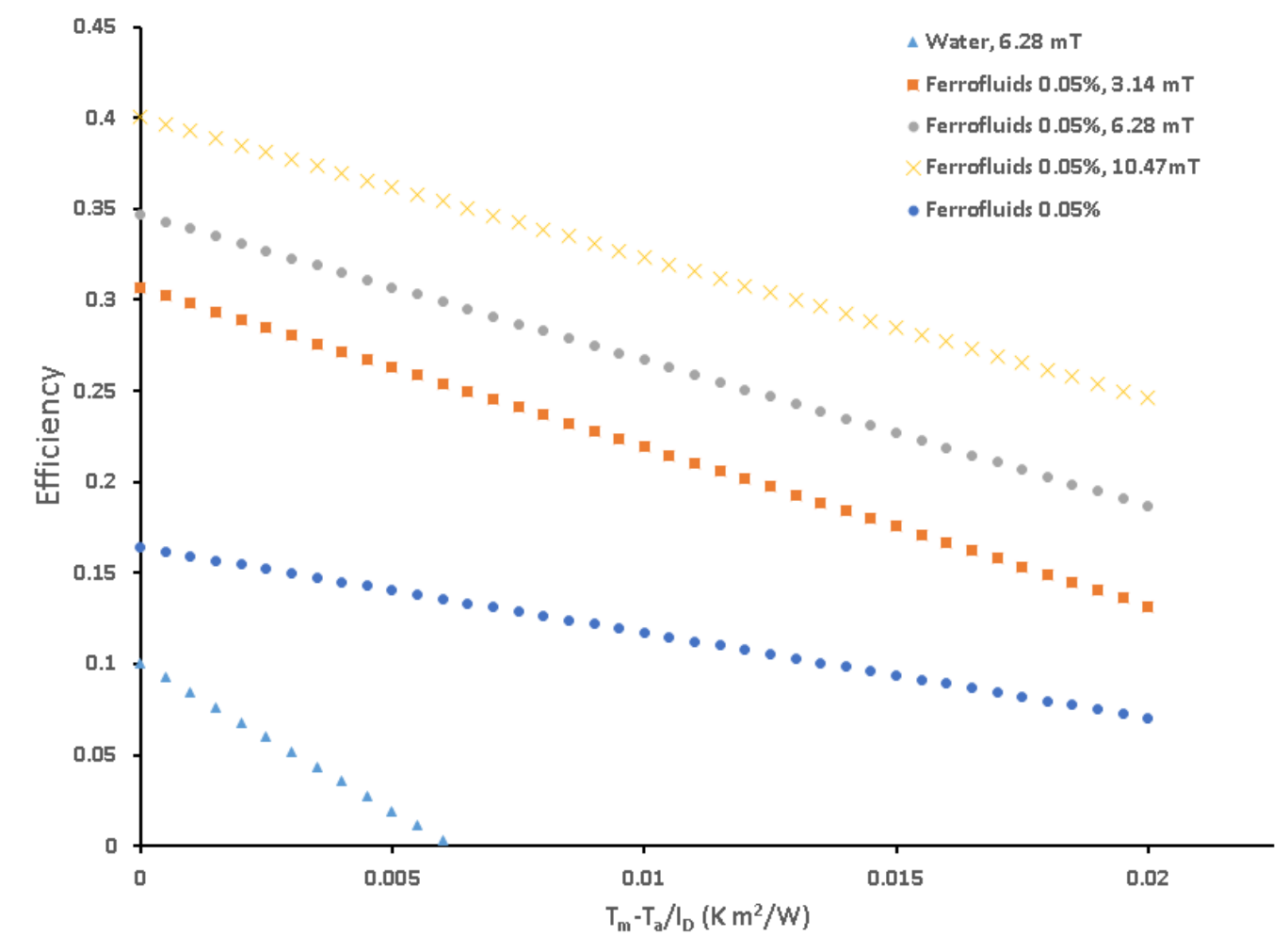

Figure 4 Thermal Efficiency of the parabolic trough with Water and Ferrofluids in the presence of an external magnetic field in the laminar region. 